\title{
Outcomes of adrenalectomy in patients with primary hyperaldosteronism - a single centre experience
}

\author{
Igor Hartmannn ${ }^{\mathrm{a}}$,Michal Grepla ${ }^{\mathrm{a}}$, Ales Vidlara ${ }^{\mathrm{a}}$, Oldrich Smakal ${ }^{\mathrm{a}}$, Jan Vaclavik ${ }^{\mathrm{b}}$, Zdenek Frysakc, Martin Dolezel ${ }^{\mathrm{d}, e, f}$, \\ Vladimir Student ${ }^{\mathrm{a}}$
}

\begin{abstract}
Introduction. Primary hyperaldosteronism is a common cause of secondary hypertension. In patients with proven unilateral overproduction of aldosterone adrenalectomy can cure hyperaldosteronism with high probability and a positive effect on hypertension. The aim of the study was to determine the effects of unilateral adrenalectomy on blood pressure and laboratory parameters. The secondary objective was to identify parameters that would allow the prediction of hypertension cure.

Methods. We performed a cross-sectional analysis of the data of patients who underwent unilateral adrenalectomy for primary aldosteronism at the Department of Urology of University Hospital Olomouc in the years 2000-2011. We assesed the preoperative clinical conditions of patients, the results of biochemical and radiological examinations, course of the surgery and post-operative course including laboratory and clinical parameters during the 12 months postoperatively. Results. 62 patients underwent adrenalectomy for primary aldosteronism in this period. Four patients were excluded from the study due to surprising histology (myelolipoma in 2, carcinoma in 2), seven patients had incomplete postoperative data. The statistical analysis therefore included 51 patients, of which $57 \%$ were females. CT or MRI was performed in all patients; $63 \%$ patients underwent superselective catheterization of adrenal veins (AVS). Adrenalectomy was performed in all cases laparoscopically. Histology most often showed adrenal hyperplasia (59\%), adenoma was detected in $37 \%$ and adenoma on the basis of micronodular hyperplasia in $4 \%$. Twelve months after surgery the antihypertensive drugs were discontinued in 17/51 (33\%) and the number or dose of antihypertensive drugs was reduced in $25 / 51$ (49\%). Normokalemia and normalisation of the aldosterone-renin ratio (ARR) was detected in $92 \%$ and $84 \%$ of the patients. Performing AVS did not statistically significantly influence the rate of blood pressure control or normalization of ARR, which is probably due to small study size. This study demonstrated a better effect of surgery on blood pressure in younger patients.

Conclusions. Unilateral adrenalectomy had a positive effect in $82 \%$ of the patients operated for primary aldosteronism and lead to either blood pressure normalization or reduction of the antihypertensive medication.
\end{abstract}

Key words: primary hyperaldosteronism, adrenalectomy, surgery, adrenal venous sampling, hypertension, adrenal adenoma, and adrenal hyperplasia

Received: March 11, 2014; Accepted with revision: November 11, 2014; Available online: December 2, 2014 http://dx.doi.org/10.5507/bp.2014.059

${ }^{a}$ Department of Urology, University Hospital Olomouc and Faculty of Medicine and Dentistry, Palacky University Olomouc, Czech Republic ${ }^{b}$ Department of Internal Medicine I - Cardiology, University Hospital Olomouc and Faculty of Medicine and Dentistry, Palacky University Olomouc

'Department of Internal Medicine III - Nephrology, Rheumatology and Endocrinology, University Hospital Olomouc and Faculty of Medicine and Dentistry, Palacky University Olomouc

${ }^{d}$ Multiscan a Pardubice Regional Hospital, Pardubice

${ }^{e}$ Department of Oncology, $1^{\text {st }}$ Faculty of Medicine, Charles University in Prague

fDepartment of Oncology, University Hospital Olomouc and Faculty of Medicine and Dentistry, Palacky University Olomouc Corresponding author: Oldrich Smakal, e-mail: smakalac@seznam.cz

\section{INTRODUCTION}

Primary hyperaldosteronism (PHA) is a disease caused by hypersecretion of aldosterone from the adrenal cortex. It is one of the most common causes of secondary hypertension with an estimated prevalence of $5-10 \%$ of patients with arterial hypertension, although in some populations the proportion of PHA is as high as $11.2 \%$ (ref. ${ }^{1-4}$ ).

PHA is most commonly caused by an aldosteroneproducing adenoma (APA), i.e. Conn's syndrome, or bilateral adrenal hyperplasia or idiopathic hyperaldosteronism
(IAH) which together account for approximately $90 \%$ of cases. Other conditions are rare. These include unilateral adrenal hyperplasia (5-6\%), familial hyperaldosteronism types I and II (2\%) and in rare cases, an aldosteroneproducing carcinoma $(1-2 \%)\left(\right.$ ref. $\left.^{5}\right)$.

The clinical picture of PHA is not very specific. There may be symptoms resulting from hypokalemia, such as muscle weakness, fatigue, constipation, paraesthesia and arrhythmias. According to current knowledge, low serum potassium is not a frequent finding today compared to reports in the past. Almost all patients with PHA suffer from moderate to severe arterial hypertension with rela- 
tively frequent resistance to antihypertensive treatment. Cardiovascular events occur more frequently than in other patients with hypertension ${ }^{6}$.

Adrenalectomy is indicated in patients with unilateral overproduction of aldosterone. Successful treatment leads to a reduction in aldosterone hyperproduction, accompanied by a positive effect on hypertension, even complete correction with normalization of hypokalemia ${ }^{7}$. Patients with IAH are treated with mineralocorticoid receptor antagonists, because unilateral adrenalectomy does not lead to improvement in clinical symptoms and bilateral adrenalectomy causes addisonism ${ }^{9}$.

For the successful surgical treatment of PHA, it is crucial to identify the sources of aldosterone overproduction. Initial efforts to do so, using imaging methods (CT, MRI) produced suboptimal results. Adenomas may in fact, be very small with a size below the threshold for resolution, they can coexist with hyperplasia, macronodular hyperplasia can mimic adenoma and common is also the presence of a hormonally inactive incidentaloma ${ }^{10}$.

Most clinics treating this condition therefore perform selective sampling of blood from the adrenal veins (AVS) (see Fig. 1a and 1b). Only properly performed sampling can help to distinguish unilateral and bilateral hypersecretion of aldosterone $e^{11-14}$.

The objective of this study was to evaluate the clinical and laboratory effects of adrenalectomy performed for PHA at our hospital. Another aim was to identify the parameters that predict a beneficial effect of surgery on hypertension.

\section{PATIENTS AND METHODS}

We performed a crosssectional analysis of the data on patients who had undergone adrenalectomy at the Department of Urology of the University Hospital in Olomouc for PHA, between 2001 and 2011. All patients were referred for surgery on the basis of endocrinological, radiological and urological examination. Postoperatively, the patients were followed-up at an institutional or local endocrinology clinic.

\section{Clinical and laboratory examination}

We identified patients with a history of hypertension that had poorly responded to pharmacotherapy and who had a confirmed overproduction of aldosterone. Hypertension was defined as a systolic blood pressure greater than $140 \mathrm{~mm} \mathrm{Hg}$ and/or diastolic higher than 90 $\mathrm{mm} \mathrm{Hg}$. In each case, we analyzed plasma renin activity (PRA), serum aldosterone (ALD), and determined the aldosterone-renin ratio (ARR). The normal range of serum aldosterone was from 10 to $172 \mathrm{pg} / \mathrm{mL}$ and PRA from 0.5 to $1.9 \mathrm{ng} / \mathrm{mL} / \mathrm{h}$. Hyperaldosteronism was defined by an ARR higher than 30. Screening laboratory tests were performed according to the guidelines with concomitant antihypertensive therapy, after withdrawal of drugs that markedly affect the ARR for at least 4 weeks (e.g. spironolactone, amiloride or potassium-wasting diuretics) ( ref. $^{9}$ ). As a confirmatory test of autonomous overproduction of

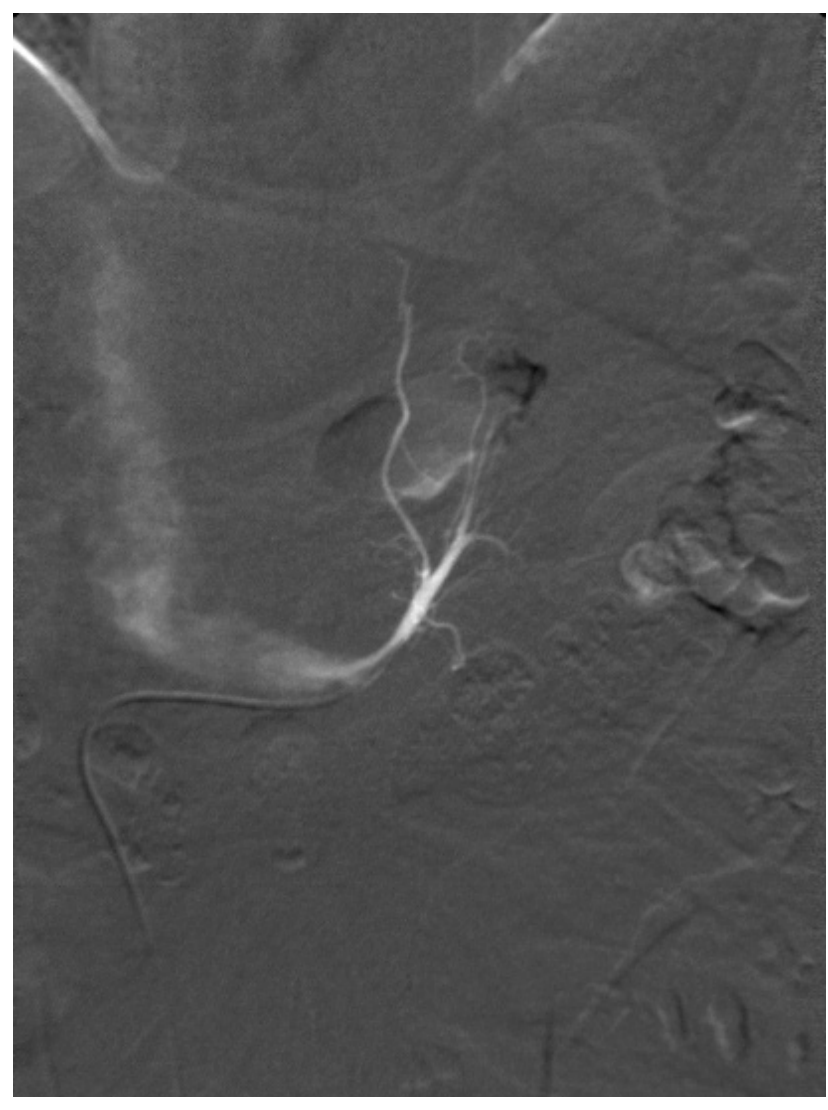

Fig. 1a. AVS of the left suprarenal vein.

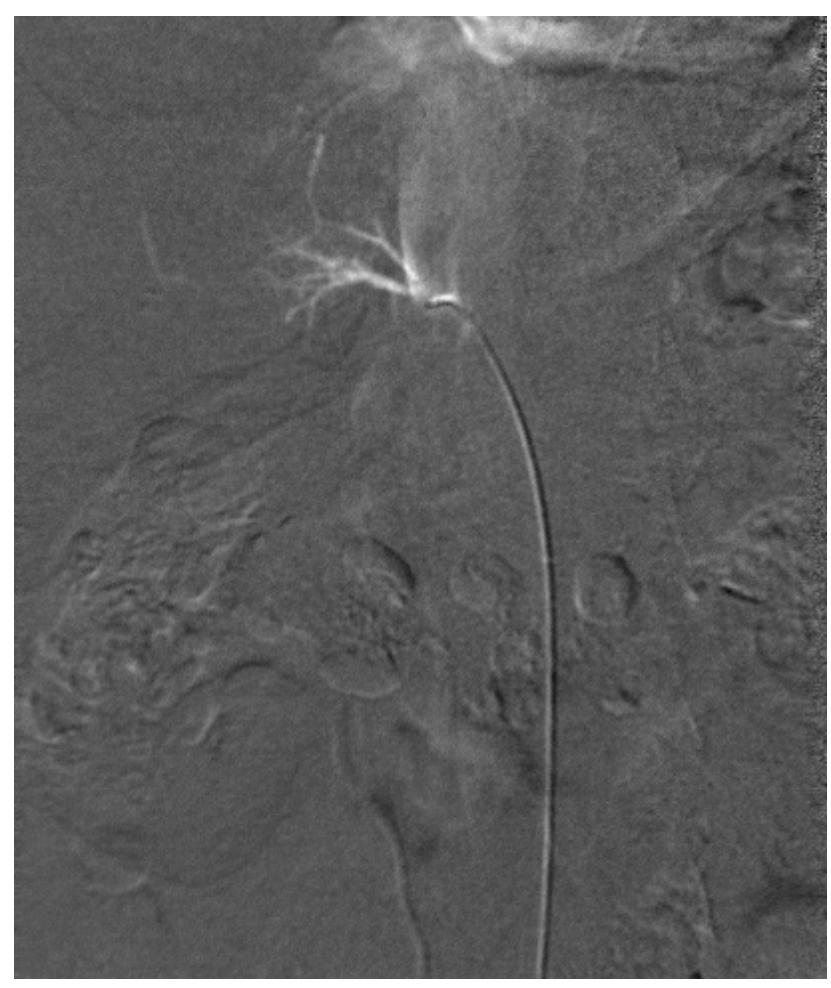

Fig. 1b. AVS of the right suprarenal vein. 
aldosterone, we used a stress test with saline infusion after discontinuation of interfering medication (patients only took calcium channel blockers and alpha blockers) in all patients who tolerated the discontinuation.

\section{Radiological examination}

All patients were examined using computed tomography $(\mathrm{CT})$ or magnetic resonance imaging (MRI). In 2006, tests of separated venous blood from superselective samplings from suprarenal veins became available. Between 2006 and 2007, the examination was carried out only in cases where the imaging method failed to identify the unilateral adrenal lesions. Since 2008, AVS was performed in all patients.

The criteria of successful catheterization is identification of a higher concentration of cortisol in the adrenal vein compared to the peripheral vein. A sufficiently selective sampling at our centre was defined as a sample with a ratio of cortisol in the adrenal vein and peripheral vein greater than 2:1.

Our criteria of successful lateralization were based on valid reccommendations ${ }^{9}$. Unilateral aldosterone hypersecretion is defined as the situation where without stimulation with ACTH the aldosterone/cortisol ratio on one side was more than 4 times greater than the other side, i.e. lateral aldosterone/cortisol ratio was above 4:1. An aldosterone/cortisol ratio below 3:1 suggests bilateral aldosterone hypersecretion. A ratio between 3:1 and 4:1 is known as the grey zone, where the correct interpretation of results should take into account the clinical status, imaging findings, or a repeated test is considered.

\section{Urological examination}

Patients who were following the endocrinologic and radiological examination indicated for unilateral adrenalectomy, were evaluated by a urologist in terms of operability. The urologist reviewed previous surgeries on the abdomen, general condition, BMI and recommended the appropriate surgery.

\section{Surgery}

The preferred surgery was laparoscopic transperitoneal adrenalectomy. Retroperitoneal adrenalectomy was not primarily considered, since this is not a preferred method at our department. In cases that we considered would preclude the laparoscopic transperitoneal approach, we indicated open surgery.

\section{Postoperative follow-up}

Patients underwent clinical and laboratory examination 3 and 12 months after surgery. We evaluated the overall health status, blood pressure, potassium levels, PRA, ALD and ARR (with concomitant use of interfering medication unless the drugs were discontinued due to hypertension cure or improvement).

\section{Statistical analysis}

Statistical analysis provides a baseline characteristics of patients before surgery. For descriptive statistics we used absolute and relative frequencies for categorical variables and means with range and median with 5-95\% percentiles for continuous variables. We also statistically evaluated clinical and laboratory values in patients 3 and 12 months after surgery.

Change in the ratio of ARR was assessed using the paired Wilcoxon test which compared values in the postoperative month 3 and 12. Univariate logistic regression model was used to assess the relations between baseline clinical and laboratory parameters (gender, age, BMI, comorbidities, duration of hypertension, number of antihypertensive drugs used, ARR, performing AVS, the ratio of aldosterone hypersecretion, the results of the histopathological analysis) and the effect of surgery on outcomes.

To determine the effect of surgery depending on implementation or non-implementation of the AVS test and the result of histological analysis, we used p-value of Fisher's exact test comparing patients with a given therapeutic effect versus the reference category.

\section{RESULTS}

Between 2000 and 2011 we performed adrenalectomy for hyperaldosteronism on 62 patients at our department. Seven patients had incomplete postoperative data. Four were excluded due to surprising results of the histology (myelolipoma in 2/62, carcinoma in 2/62). Therefore, 51 patients were included in the analysis, of whom 29 (57\%) were women and 22 (43\%) were men. The mean age of the operated patients was 57 years (34-72 years).

Patients were treated for hypertension before a diagnosis of hyperaldosteronism for an average of 143 (12-600) months. Before indication for adrenalectomy, they had used a mean of 4.2 (2-7) classes of antihypertensive drugs. Their mean BMI was 30.7 (20-42). 18 (35\%) patients did not suffer at the time of diagnosis from any other serious internal disease except for hypertension. Inother patients we noted coronary heart disease (CHD) and/or diabetes mellitus (DM). The average ARR was 267.9 (32-1484). 47 (92\%) patients had hypokalemia found during the diagnostic process.

\section{Preoperative imaging method}

In 48 patients (94\%) CT scan was performed and in the remaining $3(6 \%)$ MRI. All findings of the imaging techniques were evaluated by one expert. In 29 patients $(56 \%)$ the radiologist described a picture of unilateral adenoma, in 8 (16\%) unilateral hyperplasia (diffuse enlargement of the gland), in $5(10 \%)$ bilateral adenomas, in $3(6 \%)$ bilateral hyperplasia and in $6(12 \%)$ the imaging finding on the adrenals was negative.

AVS was performed in $32(63 \%)$ patients. The mean lateral ratio of aldosterone/cortisol secretion was 6.5 (3.031). In $15 / 32$ (47\%) cases the results of AVS corresponded to the morphological findings on imaging. In 14/32 (44\%) cases where the findings on the imaging method were bilateral or negative, the AVS adecided on the lateral indication. In 3/32 (9\%) cases the result of AVS changed the lateral indication which was suggested only on the basis of imaging methods. 


\section{Surgery}

Laparoscopic adrenalectomy was performed in all cases. In no was it necessary to proceed to open surgery. There were no major intraoperative or postoperative complications. In $3(6 \%)$ surgeries there was intraoperative blood loss greater than $400 \mathrm{ml}$. There was no need for blood transfusions. Other complications included surgical site infection - $1(2 \%)$ and pneumonia - $1(2 \%)$. No complications of grade 3 or higher according to the Clavien's scale were reported. The mean postoperative hospitalization time was $3.6(2-8)$ days.

\section{Histology}

The most common finding in the histology was adrenal hyperplasia in 30 (59\%); adenoma was detected in 19 (37\%), 2 (4\%) patients had adenoma on the basis of micronodular hyperplasia.

\section{Clinical outcome}

Three months after surgery, antihypertensive medication was discontinued and there was normalization of BP in $7(14 \%)$ patients and in $29(57 \%)$ there was a reduced dose of antihypertensive drugs. After twelve months, an- tihypertensive drugs were discontinued in 17 (33\%). The reduction in dose of antihypertensive drugs compared to baseline in $25(49 \%)$. Clinical and laboratory data for months 3 and 12 after surgery are summarized in Table 1 .

The effect of performing AVS on the resolution of hypertension 12 months potoperatively is shown in Table 2 .

We found no statistically significant benefit of AVS in this small subset of patients in terms of a diagnosis of PHA which would lead to improved hypertension control compared to patients referred on the basis of CT/MRI. Control of hypertension was the most important clinical consequence of the surgery but this was dependent on several factors. In Table 3 we therefore show the effect of AVS on the normalization of ARR 12 months after surgery. Even here, we found no statistical significance but there was a trend in favour of using AVS.

In 19 patients with a histological diagnosis of adenoma blood pressur normalized after 12 months of follow-up, in $9(47 \%)$ and in another $8(42 \%)$ the dose of antihypertensive therapy was reduced; and a positive effect on hypertension was demonstrated in a total of 17 (89\%) patients. Among 30 patients with histologically confirmed adrenal hyperplasia BP normalized in 8 (27\%), therapy

Table 1. Patients' clinical and laboratory data at 3 and 12 months postoperatively.

\begin{tabular}{|c|c|c|c|}
\hline & & 3 months postoperatively & 12 months postoperatively \\
\hline \multirow[t]{4}{*}{ Kalemia $(\mathrm{mmol} / \mathrm{L})$} & $\leq 3.6$ & $5(9.8 \%)$ & $4(7.8 \%)$ \\
\hline & $>3.6$ & $46(90.2 \%)$ & $47(92.2 \%)$ \\
\hline & Mean (min-max) & $4.5(3.1-5.6)$ & $4.5(3.2-5.6)$ \\
\hline & Median (5-95\%) & $4.5(3.3-5.3)$ & $4.5(3.4-5.3)$ \\
\hline \multirow[t]{4}{*}{ ARR } & $>30$ & $11(21.6 \%)$ & $8(15.7 \%)$ \\
\hline & $\leq 30$ & $40(78.4 \%)$ & $43(84.3 \%)$ \\
\hline & Mean (min-max) & $23.0(5.4-104.2)$ & $20.5(5.4-104.2)$ \\
\hline & Median (5-95\%) & $15.0(5.5-66.7)$ & $15.0(5.5-51.8)$ \\
\hline \multirow{10}{*}{$\begin{array}{l}\text { Number of antihypertensive } \\
\text { drug classes used }\end{array}$} & 0 & $7(13.7 \%)$ & $17(33.3 \%)$ \\
\hline & 1 & $6(11.8 \%)$ & $4(7.8 \%)$ \\
\hline & 2 & $14(27.5 \%)$ & $17(33.3 \%)$ \\
\hline & 3 & $12(23.5 \%)$ & $7(13.7 \%)$ \\
\hline & 4 & $4(7.8 \%)$ & $3(5.9 \%)$ \\
\hline & 5 & $3(5.9 \%)$ & $2(3.9 \%)$ \\
\hline & 6 & $4(7.8 \%)$ & $1(2.0 \%)$ \\
\hline & 8 & $1(2.0 \%)$ & $0(0.0 \%)$ \\
\hline & Mean (min-max) & $2.6(0.0-8.0)$ & $1.7(0.0-6.0)$ \\
\hline & Median (5-95\%) & $2.0(0.0-6.0)$ & $2.0(0.0-5.0)$ \\
\hline
\end{tabular}

Table 2. The proportions of patients based on the effect of therapy on hypertension at 12 months postoperatively out of the total patient count in whom AVS was / was not performed.

\begin{tabular}{lccc}
\hline \multirow{2}{*}{ Treatment effect at 12 months postoperatively } & \multicolumn{2}{c}{ AVS } & \multirow{2}{*}{$P^{1}$} \\
\cline { 2 - 3 } & $\begin{array}{c}\text { Not performed } \\
(\mathrm{N}=19)\end{array}$ & Performed (N=32) & Reference category \\
No effect & $5(26.3 \%)$ & $4(12.5 \%)$ & 0.419 \\
Resolved hypertension & $6(31.6 \%)$ & $11(34.4 \%)$ & 0.254 \\
Reduced medication use & $8(42.1 \%)$ & $17(53.1 \%)$ & 0.266 \\
Resolved hypertension or reduced medication use & $14(73.7 \%)$ & $28(87.5 \%)$ & \\
\hline
\end{tabular}

${ }^{1}$ Fisher's exact test $P$-value expressing the association between the proportion of patients who experience a therapeutic effect and the reference category in AVS 
was reduced in $16(53 \%)$ after 12 months. Hence an overall positive effect was demonstrated in $24(80 \%)$ patients.

Of the 32 patients who were indicated on the basis of AVS and were therefore clearly diagnosed with unilateral overproduction of aldosterone, histologically confirmed adenoma was reported in 9 (28\%) and hyperplasia in $23(72 \%)$ cases.

Prediction of normalization and/or improvement of hypertension at 12 months postoperatively are shown in Table 4 and 5.

\section{DISCUSSION}

This study shows that adrenalectomy is a highly effective mode of treatment for unilateral forms of PHA. In our cohort of patients, 33\% were normotensive and in another $49 \%$ antihypertensive medication had been reduced 12 months after the surgery. A positive effect on blood pressure was demonstrated in $82 \%$ patients, which corresponds to published studies ${ }^{15-21}$.
Previous studies have shown that independent factors for the persistence of hypertension after adrenalectomy are female sex, advanced age, increased BMI, duration of hypertension of over 6 years, more than 3 types of antihypertensive drugs used preoperatively and maximum size of the adrenal gland ${ }^{15,16,18-22}$. Zarnegar et al. proposed a scoring system predicting the benefit to patients of adrenalectomy combining four independent factors: the number of antihypertensive medications used, BMI,

Table 3. Association of normalisation of the ARR after 12 months in relation to AVS.

\begin{tabular}{cccc}
\hline \multirow{2}{*}{$\begin{array}{c}\text { Normalisation } \\
\text { of ARR }\end{array}$} & no & yes & $P^{1}$ \\
& $\mathrm{~N}=19$ & $\mathrm{~N}=32$ & \\
\hline no & $\mathrm{N}=5(26.3 \%)$ & $\mathrm{N}=3(9.4 \%)$ & 0.131 \\
yes & $\mathrm{N}=14(73.7 \%)$ & $\mathrm{N}=29(90.6 \%)$ & \\
\hline
\end{tabular}

${ }^{1}$ Fisher's exact test

Table 4. Prediction of normalization or improvement in blood pressure values at 12 months postoperatively based on baseline data.

\begin{tabular}{|c|c|c|c|c|c|}
\hline & & $\begin{array}{c}\text { No effect } \\
\text { on hypertension } \\
(\mathrm{N}=9)\end{array}$ & $\begin{array}{l}\text { Cured hypertension } \\
\text { or reduced medica- } \\
\text { tion use }(\mathrm{N}=42)\end{array}$ & OR $(95 \% \mathrm{CI})$ & $P^{2}$ \\
\hline \multirow[t]{2}{*}{ Gender } & Female & $6(20.7 \%)$ & $23(79.3 \%)$ & Reference category & \\
\hline & Male & $3(13.6 \%)$ & $19(86.4 \%)$ & $1.652(0.364-7.503)$ & 0.515 \\
\hline \multirow[t]{2}{*}{ Age } & Mean (min-max) & $62.6(53.0-71.0)$ & $55.9(34.0-72.0)$ & $0.892(0.796-0.999)$ & 0.048 \\
\hline & Median (5-95\%) & $63.0(53.0-71.0)$ & $57.5(42.0-67.0)$ & & \\
\hline \multirow{5}{*}{$\begin{array}{l}\text { Number of antihypertensives } \\
\text { used on baseline }\end{array}$} & $2-3$ & $5(27.8 \%)$ & $13(72.2 \%)$ & Reference category & \\
\hline & $4-5$ & $3(13.0 \%)$ & $20(87.0 \%)$ & $2.564(0.522-12.606)$ & 0.247 \\
\hline & $6-7$ & $1(10.0 \%)$ & $9(90.0 \%)$ & $3.462(0.344-34.843)$ & 0.292 \\
\hline & Mean (min-max) & $3.7(2.0-6.0)$ & $4.3(2.0-7.0)$ & $1.420(0.826-2.443)$ & 0.205 \\
\hline & Median (5-95\%) & $3.0(2.0-6.0)$ & $4.5(2.0-6.0)$ & & \\
\hline \multirow{2}{*}{$\begin{array}{l}\text { Duration of hypertension } \\
\text { (months) }\end{array}$} & Mean (min-max) & $133.0(45.0-280.0)$ & $145.7(12.0-600.0)$ & $1.001(0.994-1.008)$ & 0.748 \\
\hline & Median (5-95\%) & $120.0(45.0-280.0)$ & $120.0(17.0-300.0)$ & & \\
\hline \multirow[t]{2}{*}{ BMI } & Mean (min-max) & $31.9(26.0-35.0)$ & $30.4(20.0-42.0)$ & $0.926(0.784-1.093)$ & 0.363 \\
\hline & Median (5-95\%) & $31.0(26.0-35.0)$ & $31.0(23.0-38.0)$ & & \\
\hline \multirow[t]{2}{*}{ ARR } & Mean (min-max) & $143.1(42.0-562.0)$ & $294.8(34.9-1484.0)$ & $1.005(0.998-1.013)$ & 0.157 \\
\hline & Median (5-95\%) & $69.0(42.0-562.0)$ & $195.5(56.0-1000.0)$ & & \\
\hline \multirow[t]{2}{*}{ AVS } & Performed & $5(26.3 \%)$ & $14(73.7 \%)$ & Reference category & \\
\hline & Not performed & $4(12.5 \%)$ & $28(87.5 \%)$ & $2.500(0.579-10.797)$ & 0.220 \\
\hline \multirow{2}{*}{$\begin{array}{l}\text { Side-to-side ratio } \\
\text { of } \mathrm{ALD} / \text { cortisol }^{1}\end{array}$} & Mean (min-max) & $3.3(3.0-4.1)$ & $7.1(3.1-31.0)$ & $1.913(0.702-5.212)$ & 0.205 \\
\hline & Median (5-95\%) & $3.4(3.1-4.1)$ & $4.2(3.4-27.0)$ & & \\
\hline \multirow[t]{3}{*}{ DM+IHD } & no DM/IHD & $2(11.1 \%)$ & $16(88.9 \%)$ & Reference category & \\
\hline & DM or IHD & $5(16.7 \%)$ & $25(83.3 \%)$ & $0.625(0.108-3.617)$ & 0.600 \\
\hline & DM and IHD & $2(66.7 \%)$ & $1(33.3 \%)$ & $0.063(0.004-1.043)$ & 0.054 \\
\hline \multirow[t]{2}{*}{ Surgical histological findings } & Adenoma & $2(10.5 \%)$ & $17(89.5 \%)$ & Reference category & \\
\hline & Hyperplasia & $6(20.0 \%)$ & $24(80.0 \%)$ & $0.471(0.085-2.619)$ & 0.389 \\
\hline
\end{tabular}

${ }^{1}$ For patients undergoing AVS

${ }^{2} P$-value for the OR ( $P$-value for the ML chi-squared test if the OR is not stated $)$ 
Table 5. Prediction of improvement in blood pressure values at 12 months postoperatively based on baseline data.

\begin{tabular}{|c|c|c|c|c|c|}
\hline & & $\begin{array}{c}\text { No effect on } \\
\text { hypertension }(\mathrm{N}=9)\end{array}$ & $\begin{array}{l}\text { Reduced medication } \\
\text { use }(\mathrm{N}=25)\end{array}$ & OR (95\% IS) & $P^{2}$ \\
\hline \multirow[t]{2}{*}{ Gender } & female & $6(28.6 \%)$ & $15(71.4 \%)$ & Reference category & \\
\hline & male & $3(23.1 \%)$ & $10(76.9 \%)$ & $1.333(0.269-6.606)$ & 0.725 \\
\hline \multirow[t]{2}{*}{ Age } & Mean (min-max) & $62.6(53.0-71.0)$ & $58.6(43.0-67.0)$ & $0.914(0.806-1.037)$ & 0.164 \\
\hline & Median (5-95\%) & $63.0(53.0-71.0)$ & $60.0(47.0-67.0)$ & & \\
\hline \multirow[t]{5}{*}{ Number of antihypertensives } & $2-3$ & $5(50.0 \%)$ & $5(50.0 \%)$ & Reference category & \\
\hline & $4-5$ & $3(18.8 \%)$ & $13(81.3 \%)$ & $4.333(0.742-25.294)$ & 0.103 \\
\hline & $6-7$ & $1(12.5 \%)$ & $7(87.5 \%)$ & $7.000(0.613-79.871)$ & 0.117 \\
\hline & Mean (min-max) & $3.7(2.0-6.0)$ & $4.8(3.0-7.0)$ & $2.046(1.032-4.057)$ & 0.040 \\
\hline & Median (5-95\%) & $3.0(2.0-6.0)$ & $5.0(3.0-7.0)$ & & \\
\hline \multirow{2}{*}{$\begin{array}{l}\text { Duration of hypertension } \\
\text { (months) }\end{array}$} & Mean (min-max) & $133.0(45.0-280.0)$ & $182.6(36.0-600.0)$ & $1.005(0.996-1.015)$ & 0.259 \\
\hline & Median (5-95\%) & $120.0(45.0-280.0)$ & $180.0(60.0-350.0)$ & & \\
\hline \multirow[t]{2}{*}{ BMI } & Mean (min-max) & $31.9(26.0-35.0)$ & $31.0(24.0-42.0)$ & $0.941(0.770-1.149)$ & 0.550 \\
\hline & Median (5-95\%) & $31.0(26.0-35.0)$ & $31.0(25.0-37.0)$ & & \\
\hline \multirow[t]{2}{*}{ ARR } & Mean (min-max) & $143.1(42.0-562.0)$ & $282.1(40.0-1297.0)$ & $1.005(0.997-1.013)$ & 0.193 \\
\hline & Median (5-95\%) & $69.0(42.0-562.0)$ & $198.0(59.0-1000.0)$ & & \\
\hline \multirow[t]{2}{*}{ AVS } & Performed & $5(38.5 \%)$ & $8(61.5 \%)$ & Reference category & \\
\hline & Not performed & $4(19.0 \%)$ & $17(81.0 \%)$ & $2.656(0.558-12.646)$ & 0.220 \\
\hline \multirow{2}{*}{$\begin{array}{l}\text { Side-to-side ratio of ALD/ } \\
\text { cortisol }^{1}\end{array}$} & Mean (min-max) & $3.3(3.0-4.1)$ & $6,9(3.5-31.0)$ & $2.026(0.741-5.538)$ & 0.169 \\
\hline & Median (5-95\%) & $3.4(3.1-4.1)$ & $4,3(3.7-31.0)$ & & \\
\hline \multirow[t]{3}{*}{ DM+IHD } & no DM/IHD & $2(22.2 \%)$ & $7(77.8 \%)$ & Reference category & \\
\hline & DM or IHD & $5(22.7 \%)$ & $17(77.3 \%)$ & $0.971(0.151-6.247)$ & 0.976 \\
\hline & DM and IHD & $2(66.7 \%)$ & $1(33.3 \%)$ & $0.143(0.008-2.517)$ & 0.184 \\
\hline \multirow[t]{2}{*}{ Surgical histological findings } & Hyperplasia & $2(20.0 \%)$ & $8(80.0 \%)$ & Reference category & \\
\hline & Adenoma & $6(27.3 \%)$ & $16(72.7 \%)$ & $0.667(0.109-4.079)$ & 0.661 \\
\hline
\end{tabular}

${ }^{1}$ In patients who underwent AVS

${ }^{2} P$-value for OR (if OR is not stated, $P$-value of ML Ch-quadrate test is stated)

duration of hypertension, female $\operatorname{sex}^{23}$. The results show greater positive effects on hypertension in younger patients (Table 4).

It should be emphasized that the resolution or improvement in the hypertension is the most important clinical outcome of the surgery. However, hypertension is influenced by many other factors. The most accurate indicator of the effect of treatment is the change in ARR, which normalized in $84 \%$ patients in our study.

An interesting group was patients with blood pressure decrease post-operatively, but the ARR did not normalize. In our group, we had 2 patients whose ARR decreased from 210 and 140 to 45.7 respectively 43.9 . In both patients there was a reduction in dose of antihypertensive drugs from 4 to 1 respectively 2 drugs. In these patients, we can assume a certain autonomous aldosterone secretion in the solitary adrenal gland. In both cases, however, their blood pressure remains stable for the following 38 respectively 24 months postoperatively and the ARR did not deteriorate.

Adrenalectomy in hyperaldosteronism may be indicated only in cases with clearly demonstrated unilateral aldosterone hypersecretion. If the preoperative algorithm for hypersecretion localisation uses only an imaging method, up to $25 \%$ of patients will be identified incorrectly ${ }^{9,13}$. AVS is the only method able to distinguish unilateral from bilateral aldosterone hypersecretion. Most authors regard the AVS as necessary before indication for adrenalectomy in all patients with PHA, independently of the results of CT or MRI (ref.9,12). The importance of AVS increases especially in elderly patients, where the incidence of nonfunctional adenomas increases. In our group, a positive effect of surgery on hypertension in patients indicated on the basis of on the CT/MRI was $73.7 \%$, and based on AVS was $87.5 \%(P=0.266)$. Our results do not demonstrate significant benefits of AVS on hypertension control, very likely because of the small sample size that may have diminished the statistical significance. In cases of confirmed unilateral adrenal tumours larger than $4 \mathrm{~cm}$, which are indicated for adrenalectomy, given the risk of its malignant nature, we consider the indication for AVS as questionable.

Microscopically, it is not always easy to differentiate between adenoma and adrenal hyperplasia. Adrenal adenoma is usually solitary and is circumscribed by a capsule. In the case of nodular hyperplasia more nodules are 
often found and the area of the adrenal cortex outside the nodules is hyperplastic, unlike the case of adenomas, which generally present with extranodular atrophy ${ }^{24,25}$. Several histopathologists carried out the histology, thus it is not possible to clearly distinguish various forms of hyperplasia.

Traditionally, the most common cause of unilateral aldosterone hypersecretion is adrenal adenoma. This should have been reflected in the histological examination of the removed adrenal glands in our sample. However the most common finding was adrenal hyperplasia (59\%). In patients with accurately diagnosed unilateral hypersecretion the basis of the AVS, the proportion of adrenal hyperplasia was higher (72\%). Clinical outcomes of patients with histological evidence of hyperplasia are virtually identical to those in patients with evidence of adenoma. This fact is consistent with studies that consider unilateral adrenal hyperplasia as far more frequent than previously thought ${ }^{26-30}$. In recent years, new histological forms causing unilateral aldosterone hypersecretion (nodular adrenal hyperplasia, unilateral multiple adrenocortical mikronodules, primary unilateral hyperplasia) have been described ${ }^{9,26,27,30,31}$.

The diagnosis of myelolipoma we found in our sample was suprising. Myelolipomas alone do not produce aldosterone. Both patients were indicated for adrenalectomy without AVS. In one patient, there was no improvement in laboratory or clinical results after adrenalectomy. The second patient did not undergo post-operative monitoring. A patient with confirmed $8 \mathrm{~cm}$ large adrenal carcinoma developed metastases during the monitoring.

When the preoperative scans confirm solitary adrenal adenoma, some authors consider as a possible treatment partial resection of the adrenal gland in order to preserve the remaining functional adrenal gland tissue ${ }^{28}$. It is problematic to macroscopically identify exact tissues causing overproduction of aldosterone during surgery. Histological examination of the adrenal glands removed for APA demonstrated a multifocal character in $27 \%$ $\left(\right.$ ref. $\left.^{32}\right)$. In these cases, only enucleating or partial resection of adrenal gland does not have the expected therapeutic effect. Chen et al. indicate the same laboratory and clinical results during a 12-month follow-up in patients after total and partial adrenalectomy ${ }^{33}$. A large, prospective study to demonstrate the effectiveness of this surgical method is needed. At our department, partial resection of adrenal gland with solitary adrenal adenoma diagnosed using imaging methods and confirmed by ipsilateral hyperproduction is not unequivocally recommended and this is confirmed by other authors ${ }^{9,12}$.

\section{ABBREVIATIONS}

ALD, Aldosterone; ARR, Aldosterone-renin ratio; AVS, Adrenal venous sampling; BMI, Body mass index; CT, Computed tomography; IAH, Idiopathic hyperaldosteronism; MRI, Magnetic resonance imaging; PHA, Primary hyperaldosteronism; PRA, Plasma renin activity.

\section{ACKNOWLEDGEMENTS}

Supported by RVO: 61989592.

Authorship contributions: IH, JV, ZF, MD: literature search; IH, JV, ZF, MD: manuscript writing; IH, MG, JV, VS: study design; IH, MG, AV, OS, VS: data collection; IH, MG, ZF: data analysis; IH, JV, ZF: data interpretation; IH, MG: statistical analysis.

Conflict of interest statement: The authors state that there are no conflicts of interest regarding the publication of this article.

\section{REFERENCES}

1. Lund JO, Nielsen MD, Giese J. Prevalence of primary aldosteronism. Acta Med Scand 2011; 646(Suppl):54-57 2426 World J Surg (2011); 35:2422-7.

2. Rossi GP, Bernini G, Caliumi C, Desideri G, Fabris B, Ferri C, Ganzaroli C, Giacchetti G, Letizia C, Maccario M, Mallamaci F, Mannelli M, Mattarello MJ, Moretti A, Palumbo G, Parenti G, Porteri E, Semplicini A, Rizzoni D, Rossi E, Boscaro M, Pessina AC, Mantero F. A prospective study of the prevalence of primary aldosteronism in 1,125 hypertensive patients. J Am Coll Cardiol 2006; 48:2293-2300.

3. Rossi GP. Prevalence and diagnosis of primary aldosteronism. Curr Hypertens Rep 2010; 12(5):342-8.

4. Young WF Jr. Primary aldosteronism: a common and curable form of hypertension. Cardiol Rev 1999; 7:207-214.

5. Goh BK, Tan YH, Chang KT, Eng PH, Yip SK, Cheng CW. Primary hyperaldosteronism secondary to unilateral adrenal hyperplasia: an unusual cause of surgically correctable hypertension. A review of 30 cases. World J Surg 2007;31(1):72-9.

6. Milliez P, Girerd X, Plouin PF, Blacher J, Safar ME, Mourad JJ. Evidence for an increased rate of cardiovascular events in patients with primary aldosteronism. J Am Coll Cardiol 2005;45:1243-8.

7. Lumachi F, Ermani M, Basso SM, Armanini D, lacobone M, Favia G. Long-term results of adrenalectomy in patients with aldosteroneproducing adenomas: multivariate analysis of factors affecting unresolved hypertension and review of the literature. Am Surg 2005;71(10):864-9.

8. Ishidoya S, Ito A, Sakai K, Satoh M, Chiba Y, Sato F, Arai Y. Laparoscopic partial versus total adrenalectomy for aldosterone producing adenoma. J Urol. 2005;174(1):40-3.

9. Funder JW, Carey RM, Fardella C, Gomez-Sanchez CE, Mantero F, Stowasser M, Young WF Jr, Montori VM. Case detection, diagnosis, and treatment of patients with primary aldosteronism: an endocrine society clinical practice guideline. J Clin Endocrinol Metab 2008;93(9):3266-81.

10. Omura M, Sasano H, Saito J, Yamaguchi K, Kakuta Y, Nishikawa T. Clinical characteristics of aldosterone-producing microadenoma, macroadenoma, and idiopathic hyperaldosteronism in 93 patients with primary aldosteronism. Hypertens Res 2006;29(11):883-9.

11. Toniato A, Bernante P, Rossi GP, Pelizzo MR. The role of adrenal venous sampling in the surgical management of primary aldosteronism. World J Surg 2006;30:624-7.

12. Nishikawa T, Omura M, Satoh F, Shibata H, Takahashi K, Tamura N, Tanabe A. Guidelines for the diagnosis and treatment of primary aldosteronism. Task Force Committee on Primary Aldosteronism, The Japan Endocrine Society. Endocr J 2011;58(9):711-21.

13. Young WF, Stanson AW, Thompson GB, Grant CS, Farley DR, van Heerden JA. Role for adrenal venous sampling in primary aldosteronism. Surgery 2004;136:1227-35.

14. Ctvrtlik F, Koranda P, Tichý T. Adrenal disease: a clinical update and overview of imaging. A review. Biomed Pap Med Fac Univ Palacky Olomouc Czech Repub 2014;158(1):23-34. doi:10.5507/bp.2014.010

15. Lo CY, Tam PC, Kung AW, Lam KS, Wong J. Primary aldosteronism. Results of surgical treatment. Ann Surg 1996;224:125-30.

16. Brunt LM, Moley JF, Doherty GM, Lairmore TC, DeBenedetti MK, Quasebarth MA. Outcomes analysis in patients undergoing laparoscopic adrenalectomy for hormonally active adrenal tumors. Surgery 2001;130:629-34. 
17. Waldmann J, Waldmann J, Maurer L, Holler J, Kann PH, Ramaswamy A, Bartsch DK, Langer P. Outcome of surgery for primary hyperaldosteronism. World J Surg 2011;35(11):2422-7.

18. Meria P, Kempf BF, Hermieu JF, Plouin PF, Duclos JM. Laparoscopic management of primary hyperaldosteronism: clinical experience with 212 cases. J Urol 2003;169(1):32-5.

19. Pang TC, Bambach C, Monaghan JC, Sidhu SB, Bune A, Delbridge LW Sywak MS. Outcomes of laparoscopic adrenalectomy for hyperaldosteronism. ANZ J Surg 2007;77:768-73.

20. Goh BK, Tan YH, Yip SK, Eng PH, Cheng CW. Outcome of patients undergoing laparoscopic adrenalectomy for primary hyperaldosteronism. JSLS 2004;8:320-5.

21. Murashima M, Trerotola SO, Fraker DL, Han D, Townsend RR, Cohen DL. Adrenal venous sampling for primary aldosteronism and clinica outcomes after unilateral adrenalectomy: a single-center experience. J Clin Hypertens (Greenwich) 2009;11:316-23.

22. Sukor N, Gordon RD, Ku YK, Jones M, Stowasser M. Role of unilateral adrenalectomy in bilateral primary aldosteronism: a 22-year single center experience. J Clin Endocrinol Metab 2009;94:2437-45.

23. Zarnegar R, Young WF Jr, Lee J, Sweet MP, Kebebew E, Farley DR, Thompson GB, Grant CS, Clark OH, Duh QY. The aldosteronoma resolution score: predicting complete resolution of hypertension after adrenalectomy for aldosteronoma. Ann Surg 2008;247(3):511-8.

24. Lloyd RV, Douglas BR, Young WF Jr. Endocrine diseases: Atlas of nontumor pathology. First series, Facicle 1.Washington DC: AFIP; 2002:218.

25. Rosai J. Lesions of the adrenal cortex. In: Rosai J, editor. Rosai and Ackerman's surgical pathology, $9^{\text {th }}$ ed Mosby, 2004:1119.

26. Novitsky YW, Kercher KW, Rosen MJ, Cobb WS, Jyothinagaram S, Heniford BT. Clinical outcomes of laparoscopic adrenalectomy for lateralizing nodular hyperplasia. Surgery 2005; 138(6):1009-16;discussion 1016-7.

27. Hennings J, Andreasson S, Botling J, Hägg A, Sundin A, Hellman P. Long-term effects of surgical correction of adrenal hyperplasia and adenoma causing primary aldosteronism. Langenbecks Arch Surg 2010;395(2):133-7.

28. Walz MK, Gwosdz R, Levin SL, Alesina PF, Suttorp AC, Metz KA, Wenger FA, Petersenn S, Mann K, Schmid KW. Retroperitoneoscopic adrenalectomy in Conn's syndrome caused by adrenal adenomas or nodular hyperplasia. World J Surg 2008;32(5):847-53.

29. Trésallet C, Salepçioglu H, Godiris-Petit G, Hoang C, Girerd X, Menegaux F. Clinical outcome after laparoscopic adrenalectomy for primary hyperaldosteronism: the role of pathology. Surgery 2010;148(1):129-34

30. lacobone M, Citton M, Viel G, Boetto R, Bonadio I, Tropea S, Mantero F, Rossi GP, Fassina A, Nitti D, Favia G. Unilateral adrenal hyperplasia: a novel cause of surgically correctable primary hyperaldosteronism. Surgery 2012;152(6):1248-55.

31. Omura M, Sasano H, Fujiwara T, Yamaguchi K, Nishikawa T. Unique cases of unilateral hyperaldosteronemia due to multiple adrenocortical micronodules, which can only be detected by selective adrenal venous sampling. Metabolism 2002;51:350-5.

32. Ishidoya S, Ito A, Sakai K, Satoh M, Chiba Y, Sato F, Arai Y. Laparoscopic partial versus total adrenalectomy for aldosterone producing adenoma. J Urol 2005;174(1):40-3.

33. Chaen SF, Chuen SC, Wang SM, Wu VC, Pu YS, Wu KD, Huang KH. Clinical outcomes in patients undergoing laparoscopic adrenalectomy for unilateral aldosterone producing adenoma: partial versus total adrenalectomy. J Endourol 2014 Jun 30. (Epub ahead of print) 